\title{
Combination Therapy by Tissue-Specific Suicide Gene and Bevacizumab in Intramedullary Spinal Cord Tumor
}

\author{
So-Jung Gwak ${ }^{1,2}$, Lihua Che ${ }^{2,3}$, Yeomin Yun ${ }^{2,3}$, Minhyung Lee ${ }^{4}$, and Yoon $\mathrm{Ha}^{2,3}$ \\ ${ }^{1}$ Department of Chemical Engineering, Wonkwang University, Iksan; \\ ${ }^{2}$ Department of Neurosurgery, Yonsei University College of Medicine, Seoul; \\ ${ }^{3}$ Brain Korea 21 PLUS Project for Medical Science, Yonsei University College of Medicine, Seoul; \\ ${ }^{4}$ Department of Bioengineering, College of Engineering, Hanyang University, Seoul, Korea.
}

Purpose: Malignant gliomas are aggressive spinal cord tumors. In this study, we hypothesized that combination therapy using an anti-angiogenic agent, bevacizumab, and hypoxia-inducible glioblastoma-specific suicide gene could reduce tumor growth.

Materials and Methods: In the present study, we evaluated the effect of combination therapy using bevacizumab and pEpo-NI2SV-TK in reducing the proliferation of $\mathrm{C} 6$ cells and tumor growth in the spinal cord. Spinal cord tumor was generated by the injection of $\mathrm{C} 6$ cells into the T5 level of the spinal cord. Complexes of branched polyethylenimine (bPEI)/pEpo-NI2-SV-TK were injected into the spinal cord tumor. Bevacizumab was then administered by an intraperitoneal injection at a dose of $7 \mathrm{mg} / \mathrm{kg}$. The anti-cancer effects of combination therapy were analyzed by histological analyses and magnetic resonance imaging (MRI). The Basso, Beattie and Bresnahan scale scores for all of the treatment groups were recorded every other day for 15 days to assess the rat hindlimb strength.

Results: The complexes of bPEI/pEpo-NI2-SV-TK inhibited the viability of C6 cells in the hypoxia condition at 5 days after treatment with ganciclovir. Bevacizumab was decreased in the cell viability of human umbilical vein endothelial cells. Combination therapy reduced the tumor size by histological analyses and MRI. The combination therapy group showed improved hind-limb function compared to the other groups that were administered pEpo-NI2-SV-TK alone or bevacizumab alone.

Conclusion: This study suggests that combination therapy using bevacizumab with the pEpo-NI2-SV-TK therapeutic gene could be useful for increasing its therapeutic benefits for intramedullary spinal cord tumors.

Key Words: Bevacizumab, TK, erythropoietin enhancer, spinal cord, tumor

\section{INTRODUCTION}

Intramedullary spinal cord tumors (IMSCTs) possess approximately $4-10 \%$ of all central nervous system (CNS) tumors. ${ }^{1,2}$ Surgery is the main treatment method for IMSCTs; however, the involvement of neural tracts in IMSCTs makes it difficult to completely cure them by surgery. ${ }^{3,4}$ Recently, radiotherapy or

Received: June 18, 2020 Revised: September 11, 2020

Accepted: October 19, 2020

Corresponding author: Yoon Ha, MD, PhD, Department of Neurosurgery, Yonsei University College of Medicine, 50-1 Yonsei-ro, Seodaemun-gu, Seoul 03722, Korea. Tel: 82-2-2228-2150, Fax: 82-2-393-9979, E-mail: hayoon@yuhs.ac

-The authors have no potential conflicts of interest to disclose.

(c) Copyright: Yonsei University College of Medicine 2020

This is an Open Access article distributed under the terms of the Creative Commons Attribution Non-Commercial License (https://creativecommons.org/licenses/ by-nc/4.0) which permits unrestricted non-commercial use, distribution, and reproduction in any medium, provided the original work is properly cited. chemotherapy after surgery are being considered as external modes of therapy for IMCSTs. A multi-disciplinary mode of treatment, involving maximal surgical resection along with radiotherapy-combined temozolomide, allows the patients to experience an average survival time of less than 2 years. ${ }^{5,6}$

Many studies have reported that combination treatments, such as chemotherapy, gene therapy, or radiotherapy display, improved the anti-cancer efficacy of glioblastomas in the spinal cord or the brain. ${ }^{7,8}$ Currently, the application of combination therapy using an anti-angiogenic agent and chemotherapy has been found to show higher therapeutic efficacy in the treatment of brain glioblastoma compared to any single mode of therapy alone. ${ }^{4,9}$ Bevacizumab is a monoclonal antibody that serves as an anti-angiogenic agent by targeting the vascular endothelial growth factor (VEGF) and inhibiting angiogenesis. ${ }^{10}$ It has been approved by the FDA as a first-line treatment for combination therapy of cancer. ${ }^{11}$ Pre-clinical evidence and 
clinical trials have confirmed that bevacizumab inhibits tumor progression by targeting abnormal tumor vessels. ${ }^{12,13}$ Bevacizumab therapy causes devascularization and hypoxia-like conditions in tumors. ${ }^{12}$

Tissue-specific gene delivery systems have been developed to increase the efficacy and safety by inducing protein expression after gene delivery and minimizing damage to normal cells. ${ }^{14}$ The glioma dual-specific TK gene increases the therapeutic efficacy in brain tumor tissues without side effect. ${ }^{15,16}$ Transcription regulation has been investigated using tissuespecific promoters, such as the glial fibrillary acidic protein (GFAP) promoter or nestin intron 2 (NI2).${ }^{17,18} \mathrm{Kim}$, et al. ${ }^{15}$ reported that the use of Epo enhancer with NI2 dual-specific herpes simplex virus thymidine kinase gene (HSV-TK) and ganciclovir (GCV) is a powerful gene therapy strategy for malignant gliomas. ${ }^{19}$ The solid tumor-like glioblastoma grows rapidly, leading to a lack of blood supply. ${ }^{20,21}$ This results in a significantly low oxygen concentration in the tumor compared to the normal tissue, due to the rapid proliferation of tumor cells and the limited amount of oxygen available to diffuse into the tumor tissue. ${ }^{22}$ Previous studies have shown that the Epo enhancer increases gene expression in glioblastoma under the condition of hypoxia, while NI2 induces gene expression in neural stem cells or glioblastoma. ${ }^{23-25}$ In this study, we developed a novel therapy using a combination of bevacizumab, hypoxia, and the glioma dual-specific gene, pEpo-NI2-SV-TK, for the treatment of IMSCTs. We investigated whether a combination therapy involving bevacizumab and pEpo-NI2-SV-TK has enhanced anti-cancer effects on IMSCTs compared to using conventional therapies alone.

\section{MATERIALS AND METHODS}

\section{Plasmid construction}

The plasmids, pEpo-NI2-SV-Luci and pEpo-NI2-SV-TK, were constructed with the elements, Epo enhancer, NI2, and pSVHSV-TK, as described previously. ${ }^{15}$ All of the plasmids used in this study, including pSV-Luci (Promega, Madison, WI, USA), were provided by Professor Minhyung Lee. The plasmids were transformed into Escherichia coli DH5- $\alpha$ (RBC, Taipei, Taiwan) and cultured in Luria-Bertani broth medium containing $50 \mu \mathrm{g} / \mathrm{mL}$ ampicillin at $37^{\circ} \mathrm{C}$ overnight with continuous shaking at $250 \mathrm{rpm}$. The amplified plasmids were purified using the Endofree Maxi plasmid purification kit (Qiagen, Venlo, the Netherlands), according to the manufacturer's instructions. The plasmid DNA (pDNA) was quantified using a Nanodrop spectrophotometer (ND-1000, Thermo Fisher Scientific, Waltham, MA, USA) at a wavelength of $260 \mathrm{~nm}$.

\section{Cell culture}

C6 (rat glioma) cells and human embryonic kidney (HEK 293) cells were maintained in Dulbecco's modified Eagle's medium
(DMEM, Gibco, Grand Island, NY, USA) supplemented with $10 \%$ fetal bovine serum (FBS; Hyclone, Logan, UT, USA) and $1 \%$ penicillin/streptomycin (Gibco). To establish stable DsRedexpressing C6 cells, the complexes of the pBudCE4.1-DsRed plasmid with lipofectamine (Invitrogen, Carlsbad, CA, USA) were transfected into C6 cells, according to a previously described protocol. ${ }^{4}$ The DsRed-expressing cells were selected using Zeocin (Invitrogen). Human umbilical vein endothelial cells (HUVECs) were maintained in endothelial cell basal medium supplemented with endothelial cell growth medium (EGM-2) Bulletkit (Lonza, Walkersville, MD, USA) on culture dishes coated with $1 \mu \mathrm{g} / \mathrm{cm}^{2}$ human fibronectin (Sigma, St. Louis, MO, USA). The culture medium was replaced every other day.

\section{Measurement of transfection efficiency and luciferase assay for the dual-specific gene}

C6 and HEK 293 cells were plated into 6-well plates at a density of $2 \times 10^{5}$ cells/well and cultured overnight. Complexes of branched polyethylenimine (bPEI) (molecular weight: 25000 $\mathrm{Da}$, Sigma) and the various pDNAs were prepared with an N/ $\mathrm{P}$ ratio of 5, according to previous reports. ${ }^{26}$ Before transfection, the medium was replaced with serum-free DMEM. The $\mathrm{bPEI} / \mathrm{pDNA}$ complexes were added to each well at a dosage of $2 \mu \mathrm{g}$ pDNA/well, and the cells were incubated for $4 \mathrm{~h}$. After the 4-h incubation, the medium was replaced with a fresh medium containing $10 \%$ FBS. The cells were incubated for an additional $44 \mathrm{~h}$ under the conditions of hypoxia $\left(1 \% \mathrm{O}_{2}\right)$ or normoxia $\left(20 \% \mathrm{O}_{2}\right)$. To evaluate the luciferase expression, luciferase activity was measured using the Promega Luciferase Assay System, in accordance with the manufacturer's protocol (Promega). Cells were washed with phosphate buffered saline (PBS) and then homogenized using 1x Reporter Lysis Buffer (Promega). The lysates were then incubated for $1 \mathrm{~h}$ on ice, followed by centrifugation at $13000 \times \mathrm{g}$ for $10 \mathrm{~min}$. The transfection efficiency of the various pDNAs was measured using a VersaMax enzyme-linked immunosorbent assay (ELISA) microplate reader (Molecular Devices, Sunnyvale, CA, USA). The total protein content in the supernatants was determined using a bicinchoninic acid protein assay kit (Pierce Biotechnology, Rockford, IL, USA). Luciferase activity has been expressed as relative light units/mg protein.

\section{In vitro effects of the dual-specific TK gene and GCV}

To evaluate the effects of the dual-specific TK gene and GCV, the complexes of bPEI with pSV-TK or pEpo-NI2-TK were prepared with an N/P ratio of 5. C6 cells were plated into 12-well plates at a density of $5 \times 10^{4}$ cells/well and cultured for $24 \mathrm{~h}$. The bPEI complexes were added to each well and incubated with the cells for $4 \mathrm{~h}$. After incubation, the medium was replaced with fresh DMEM medium containing $10 \%$ FBS and 10 $\mu \mathrm{g} / \mathrm{mL}$ GCV. The cells were then incubated for 2 or 5 days under hypoxic conditions. 


\section{In vitro effects of bevacizumab}

The effects of bevacizumab were determined by measuring the mitochondrial metabolic activity of C6 cells and HUVECs treated with various concentrations of bevacizumab (Avastin, Roche, Basel, Switzerland) using an 4.1. 3-(4,5-dimethylthiazol-2-yl)-2,5-diphenyl tetrazolium bromide (MTT) assay. C6 cells and HUVECs were plated in 96-well plates at a density of $2 \times 10^{4}$ cells/well and cultured overnight. Various concentrations of bevacizumab (Roche Korea Co. Ltd., Seoul, Korea) were added to each respective well of the plates. After incubation for 3 days at $37^{\circ} \mathrm{C}$, the cultured cells were rinsed with PBS, and 200 $\mu \mathrm{L}$ MTT (Thiazolyl Blue Tetrazolium Bromide, Sigma-Aldrich, $2 \mathrm{mg} / \mathrm{mL}$ in media, Sigma) was added to the cells. The plates were incubated for an additional $4 \mathrm{~h}$ at $37^{\circ} \mathrm{C}$, after which the MTT solution was removed. The resulting insoluble particles were dissolved in $100 \mu \mathrm{L}$ dimethyl sulfoxide Hybri-max ${ }^{\mathrm{TM}}$ (Sigma) for $30 \mathrm{~min}$ to dissolve the formazan crystals, followed by the measurement of absorbance at a wavelength of $540 \mathrm{~nm}$ using an ELISA plate reader.

\section{Anti-cancer efficacy of bevacizumab and dual-specific TK gene in a spinal cord tumor model}

The Animal Care and Use Committee of the Medical Research Institute of Yonsei University College of Medicine approved all of the protocols used in this study. Experiments were performed according to the international guidelines on ethical use of animals; minimal number of animals was used in this study. Spinal cord tumors were generated in adult male Sprague Dawley rats (250-300 g; n=28, Orient Bio, Seongnam, Korea) as described below. Sprague Dawley rat were anesthetized using Zoletil (30 mg/kg, Virbac, Carros, France), and an incision was made over the dorsal T6 level. After that, laminectomy was performed at the $\mathrm{T} 5$ level using an orthopedic bone cutter, and $1 \times 10^{5} \mathrm{C} 6$ glioma cells dissolved in $3 \mu \mathrm{L}$ PBS were injected into the $\mathrm{T} 5$ position using a Hamilton syringe (Hamilton, Bonaduz, Switzerland). Five days after the injection of C6 cells, the rats were randomly assigned to four experimental groups ( $n=7$ for each group). The control group received an injection of $10 \mu \mathrm{L}$ serum-free medium at the same injection site as the C6 cells. The TK alone group was injected with the complexes of $10 \mu \mathrm{g}$ bPEI+pEpo-NI2-TK at the tumor site, followed by an intraperitoneal (I.P.) injection of $40 \mathrm{mg} / \mathrm{kg} \mathrm{GCV}$ every day for the next 10 days. The bevacizumab alone group was given an I.P. injection of $7 \mathrm{mg} / \mathrm{kg}$ bevacizumab every other day for the next 10 days. The combination therapy group was given an I.P. injection of $10 \mu \mathrm{g} \mathrm{bPEI} / \mathrm{pEpo-NI2-TK} \mathrm{complexes} \mathrm{at} \mathrm{the} \mathrm{same}$ injection site as the C6 cells, followed by I.P. injections of 40 $\mathrm{mg} / \mathrm{kg} \mathrm{GCV}$ every day and $7 \mathrm{mg} / \mathrm{kg}$ bevacizumab every other day for the next 10 days.

\section{Histological analysis and functional tests}

Rat hind-limb strength was assessed using the Basso, Beattie and Bresnahan (BBB) scale. ${ }^{27}$ The BBB locomotor scale has a wide range of evaluation for hindlimb movement, plantar stepping, coordinated limb movement, toe clearance, parallel paw position throughout the stem cycle, and tail consistently up. The BBB scores for all of the rats were tested pre-operatively to ensure a baseline locomotor rating of 21. The BBB score of 0 indicated no observable hindlimb movement after spinal cord injury.

Rats were placed in an open field testing area, allowed to adaptm and then observed for $5 \mathrm{~min}$. After the operation, the BBB scores for all treatment groups were recorded every other day for 15 days. After the final injection, the rats were sacrificed and perfused with saline containing $4 \%$ paraformaldehyde (Merck, Frankfurt, Germany). The tumor regions were dissected and sectioned to a thickness of $10 \mu \mathrm{m}$ for histological analyses. The sections were processed for standard hematoxylin and eosin (H\&E) staining. To evaluate the effect of the dualspecific TK gene in spinal cord tumors, the sections prepared from areas that were approximately $0.5 \mathrm{~mm}$ and $1 \mathrm{~mm}$ lateral to the tumor injection site were observed by H\&E staining.

\section{Magnetic resonance imaging (MRI)}

MRI was performed four times for each spinal cord tissue sample. For the detection of tumors, MRI was conducted using a Bruker 9.4T BioSpec scanner (Bruker Corporation, Ettlingen, Germany). A transverse T2-weighted RARE sequence with the following parameters was used: repetition time/effective echo time, 2000/9 ms; RARE factor, 2; in-plane resolution, 0.156× $0.156 \mathrm{~mm}$; slice thickness, $0.5 \mathrm{~mm}$.

\section{Statistical analysis}

Quantitative data were expressed as the mean \pm standard deviation. Statistically analysis was performed by one-way ANOVA with the least significant difference method. Student's t-test was used to perform post-hoc comparisons of the sub-groups. All statistical analyses were performed using the SPSS software (version 21; IBM Corp., Armonk, NY, USA), and $p$-values less than 0.05 were considered statistically significant.

\section{RESULTS}

\section{Transfection efficacy of dual-specific plasmid}

To evaluate the effect of the glioma-hypoxia dual-specific gene, bPEI/pEpo-NI2-SV-Luci complexes were transfected into C6 glioma cells and HEK 293 cells under the conditions of normoxia or hypoxia. As a control, bPEI/pSV-Luci complexes were also transfected into the $\mathrm{C} 6$ glioma cells. In C6 cells, the luciferase activity of bPEI/pEpo-NI2-SV-Luci complexes was found to increase in the conditions of both normoxia and hypoxia. The luciferase activity of the bPEI/pEpo-NI2-SV-Luci complexes was approximately four times higher in hypoxia compared to normoxia (Fig. 1A). However, the luciferase activity of the bPEI/pSV-Luci complexes was not significantly different in 

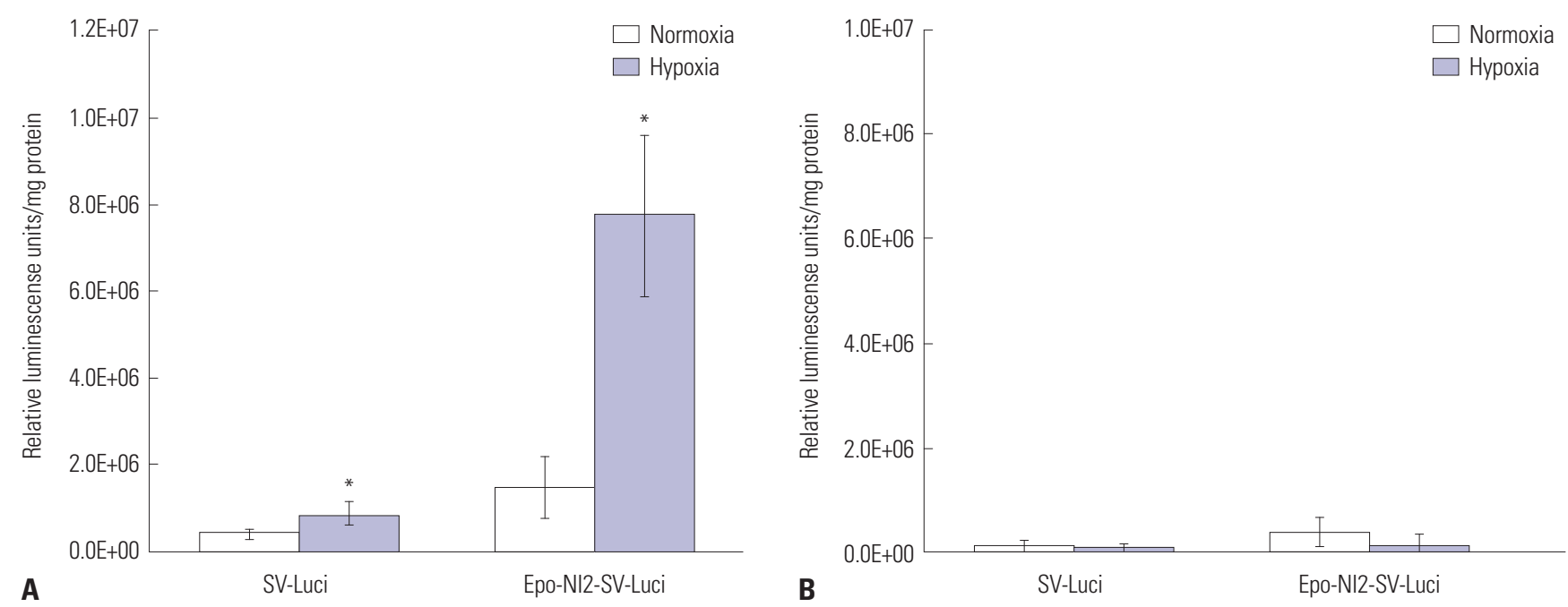

Fig. 1. Dual-specific gene expression of luciferase gene by bPEI/Epo-NI2-SV-Luci. The bPEI/pSV-Luci and bPEI/pEpo-NI2-SV-Luci were transfected into (A) C6 cells and (B) HEK 293 cells. The cells were incubated for 2 days under normoxic or hypoxic conditions and assessed for luciferase activity. The data are expressed as the mean \pm standard deviation of six independent experiments. ${ }^{*} p<0.05$ compared to the normoxia group. bPEl, branched polyethylenimine; HEK, human embryonic kidney.
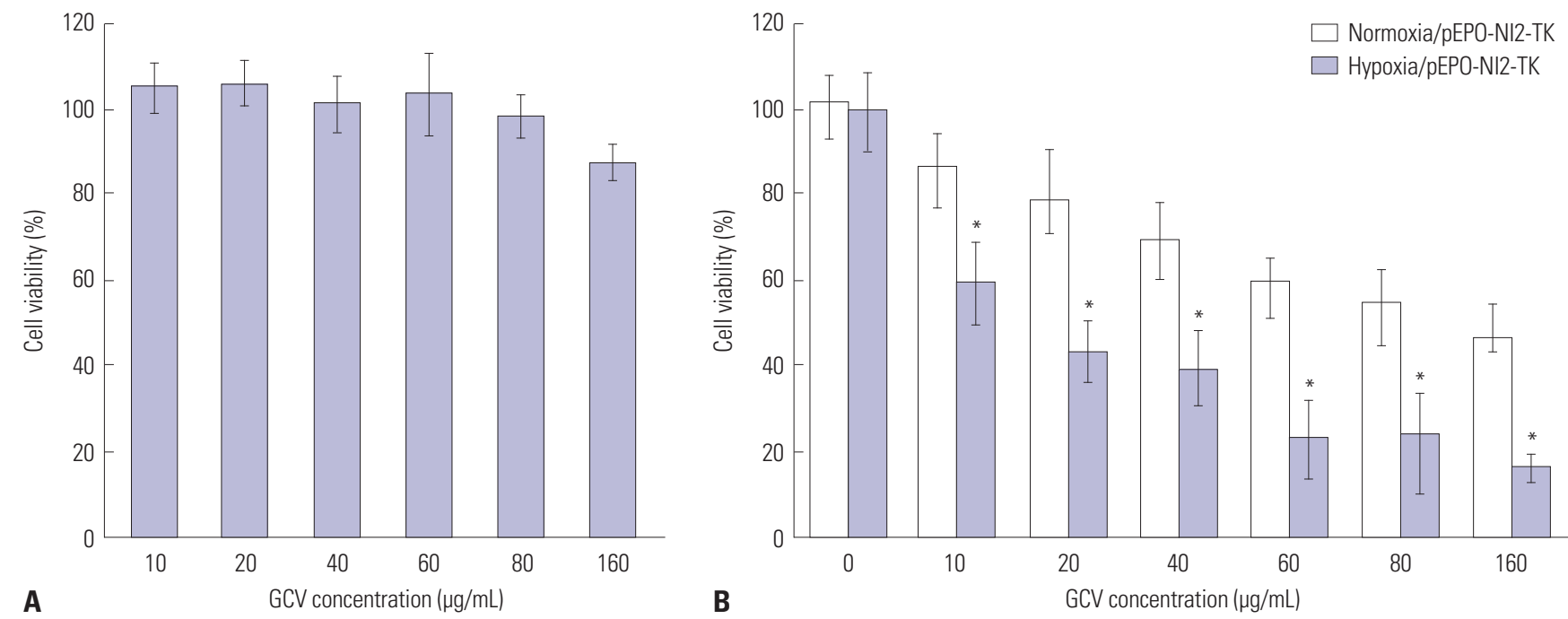

Fig. 2. Cell viability, as measured by MTT assay, after transfection of bPEI/NI2-SV-TK complexes into C6 cells followed by GCV treatment. (A) C6 cell viability after treatment with various concentrations of GCV and (B) cell viability at 2 or 5 days after transfection with bPEI/NI2-SV-TK complexes followed by GCV treatment under the condition of hypoxia. ${ }^{*} p<0.05$ compared to the group not treated with GCV. MTT, 4.1. 3-(4,5-dimethylthiazol-2-yl)-2,5-diphenyl tetrazolium bromide; bPEl, branched polyethylenimine; GCV, ganciclovir.

the normoxia and hypoxia conditions. In contrast, in HEK 293 cells, there was no significant difference in the luciferase activity of the bPEI+pEpo-NI2-SV-Luci complex under normoxia and hypoxia (Fig. 1B). The bPEI/pEPO-NI2-SV-Luci complexes significantly induced the luciferase expression in C6 cells. These results showed that the plasmid pEpo-NI2-SV-Luci causes increased gene expression under hypoxia, and this effect is specific to the cell type.

\section{Effects of dual-specific TK gene in hypoxia condition} To optimize the amount of GCV treatment after the transfection of bPEI/pEpo-NI2-SV-TK complexes into glioma, we evaluated the cell viability 2 days after treatment with various concentra- tions of GCV using an MTT assay. The cell proliferation rate of C6 cells treated with $80 \mu \mathrm{g} / \mathrm{mL}$ GCV was not significantly different from those treated with $10 \mu \mathrm{g} / \mathrm{mL}$ GCV (Fig. 2A). To determine whether the glioma and hypoxia-specific effects of the TK gene were dependent on the concentration of GCV, we transfected the bPEI/pEpo-NI2-SV-TK complexes into C6 glioma cells and incubated them with various concentrations of GCV for 5 days under the conditions of hypoxia and normoxia. At the end of 5 days, cell viability in the groups treated with bPEI/pEpo-NI2-SV-TK complexes were found to be significantly different under hypoxia and normoxia conditions. In addition, the cell viability was found to decrease with an increase in GCV concentration (Fig. 2B). 

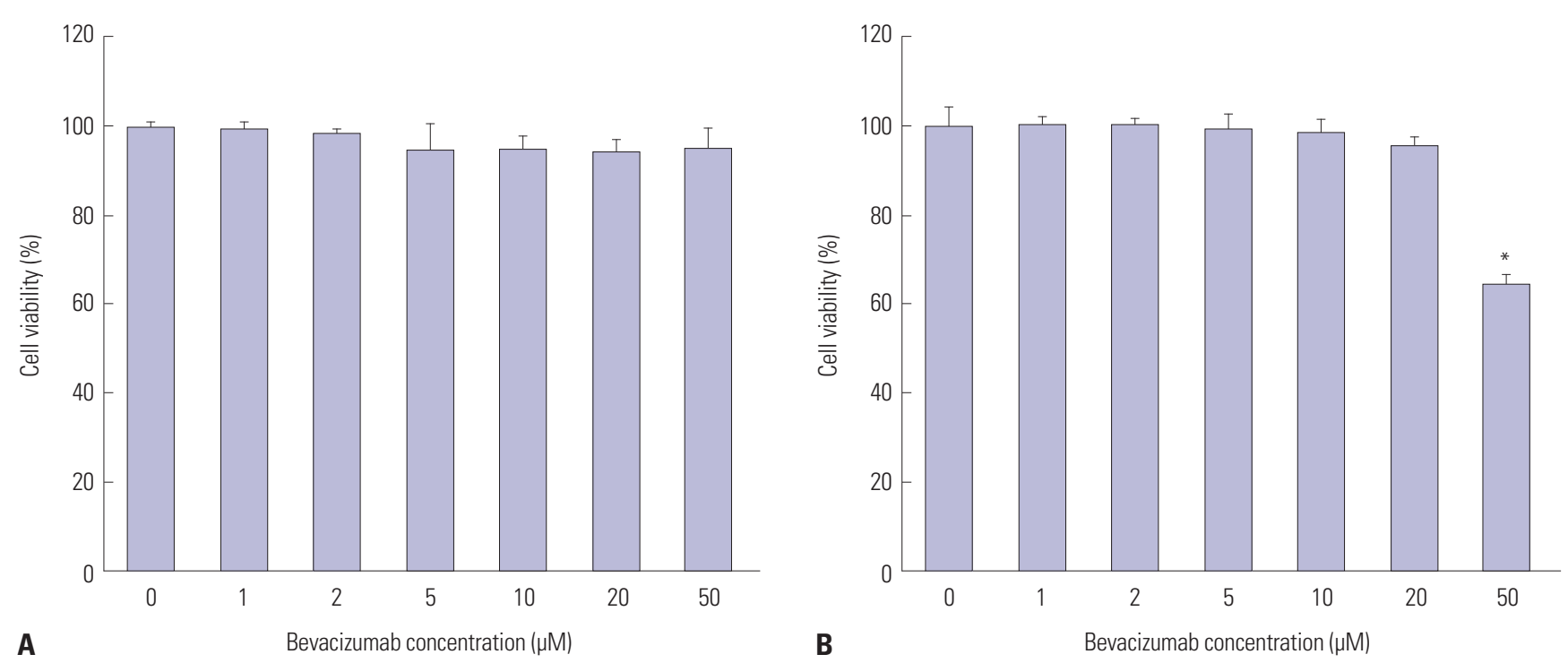

Fig. 3. Cell viability 5 days after bevacizumab treatment in (A) C6 cells and (B) human umbilical vein endothelial cells. ${ }^{*} p<0.05$ compared to the group not treated with bevacizumab.

\section{Effect of bevacizumab on C6 glioma cells and HUVECs}

We evaluated the effects of various concentrations of bevacizumab on the cytotoxicity of C6 cells and HUVECs using MTT assay. C6 glioma cells and HUVECs were treated with bevacizumab for 5 days. Bevacizumab is an angiogenesis inhibitor and reduces HUVEC proliferation. ${ }^{13}$ Five days after treatment with varying concentrations of bevacizumab, there was no inhibition in the proliferation of C6 cells (Fig. 3A). In contrast, in HUVECs, there was a significant decrease in the cell viability rate in the group treated with $50 \mu \mathrm{M}$ bevacizumab compared to the untreated control group $(p<0.05)$ (Fig. 3B).

\section{Effects of treatment with TK gene with GCV and Bevacizumab on spinal cord tumors}

The anti-cancer effects of the combination therapy were evaluated 15 days after the injection of $\mathrm{C} 6$ cells into the spinal cord by measuring the hind-limb function. Hind-limb function was evaluated every other day for 15 days after the injection of C6 glioma cells. The median hind-limb BBB score for the four groups was 18 at 5 days post-injection of $\mathrm{C} 6$ glioma cells (Fig. 4). The BBB score of the control group started to decline on Day 9, and reached 5.2 on Day 15. The BBB score of the bPEI/pSVTK complexes-treated group began to decline on Day 9 and reached approximately 8 on Day 15, while the BBB score of the bevacizumab-treated group started declining on Day 9 and reached approximately 10 on Day 15.

The anti-cancer effects of the various test treatments were also evaluated by performing histological analyses and MRI of the tumor area 15 days post-injection of the C6 cells (Fig. 5). Histological analyses showed the tumor area in the $\mathrm{T} 5$ region. Fig. 5 shows representative images of H\&E-stained sections of spinal cord tumors from the various animal groups and labeled C6 cells in the spinal cord. We observed fewer labeled C6 cells in the spinal cord from the combination-treated group

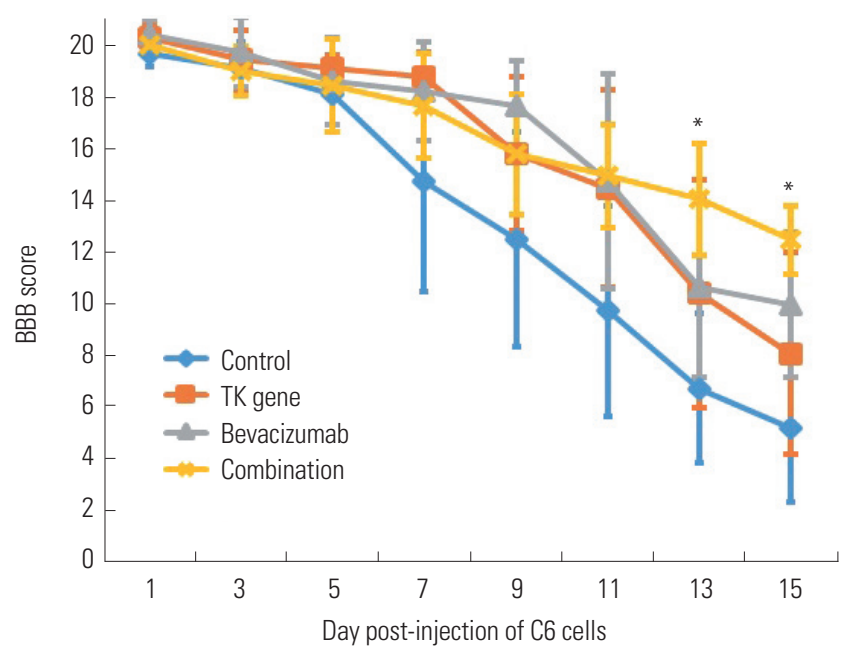

Fig. 4. Functional test of hind-limb strength. Hind-limb function was assessed using the BBB score every other day for 15 days after C6 glioma cell injection into the spinal cord. * $p<0.05$ combination therapy group compared to bPEI/pEpo-NI2-SV-TK complex-treated group at 13 days and 15 days. BBB, Basso, Beattie and Bresnahan; bPEI, branched polyethylenimine.

compared to other groups. The combined treatment with bevacizumab and dual-specific TKgene significantly reduced the tumor area compared to other treatments (Fig. 5). In the control group, nearly the entire area of the spinal cord was covered with the tumor. Compared to the control group, the groups treated with bevacizumab alone or the dual-specific TK gene alone showed greater inhibition of tumor growth in the spinal cord. The sagittal view of MRI indicated that the combined therapy of bevacizumab and dual-specific pTK gene inhibits IMSCT much more efficiently than treatment by bevacizumab or TK gene alone (Fig. 5C). 

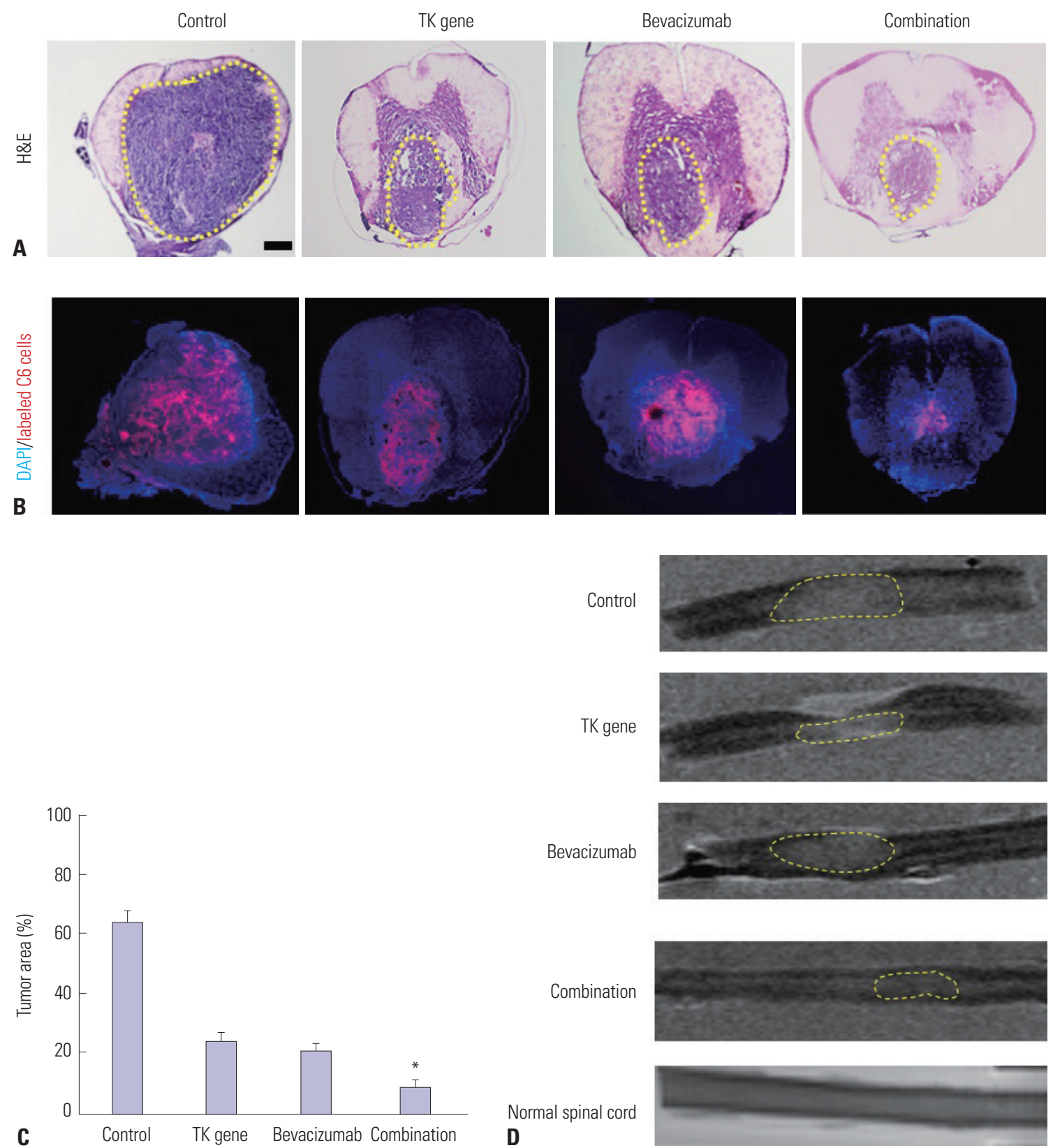

Fig. 5. Assessment of tumor size in the spinal cord after treatment. (A) H\&E staining of IMSCT sections 10 days post-treatment with complexes and bevacizumab. The dotted yellow lines indicate the IMSCT area. (B) Photomicrographs of DsRed-expressing C6 glioma cells (red) in the spinal cord. Blue color indicates the spinal cord. Scale bar: $500 \mu \mathrm{m}$. The area occupied by DsRed-expressing cells was smaller in the combination treatment group than in the other groups. (C) Tumor area in spinal cord by cross section. (D) MRI analysis of IMSCTs. * $p<0.05$ combination therapy group compared to bPEI/pEpo-NI2-SVTK complex-treated group, bevacizumab and control. H\&E, hematoxylin and eosin; DAPI, 4,6-diamidino-2-phenylindole; IMSCTs, intramedullary spinal cord tumors; $\mathrm{MRI}$, magnetic resonance imaging; bPEl, branched polyethylenimine.

\section{DISCUSSION}

The current treatment methods for IMSCTs includes surgery, chemotherapy, and radiotherapy ${ }^{28,29}$ Recently, clinical advances in multi-modality treatment, such as chemotherapy combined with radiotherapy, have led to an increase in the survival rate of patients with IMSCTs. ${ }^{30}$ In addition to these methods, gene therapy has been explored as a possible alternative approach to overcome IMSCTs. ${ }^{31}$ This study showed that treat- ment using a combination of gene therapy and bevacizumab reduced the growth of spinal cord tumors with greater efficacy compared to using any treatment alone.

Combination treatment involving both dual-specific TK gene and bevacizumab inhibited the growth of tumor. $\mathrm{Oh}$, et al. ${ }^{16}$ reported that combination therapy involving both glioblastoma-specific TK gene/R7L10 with bevacizumab to treat brain tumor reduced the tumor volume by approximately $50 \%$. Also, combination therapy with mesenchymal-epithelial tran- 
sition factor siRNA and VEGF siRNA for the reduction of VEGF expression decelerated cell growth more efficiently as compared to siRNA transfection alone. ${ }^{32}$ Here, we evaluated the anti-tumor effects of combination therapy of hypoxia-glioma dual-specific TK gene and bevacizumab in rat spinal cord tumors. Combination therapy of bPEI/dual specific TK gene and bevacizumab caused a slow decline in the hind-limb BBB scores and an approximately 2-fold decrease in the tumor area compared to treatment by bPEI/ dual-specific TK gene alone or bevacizumab alone (Fig. 5). These results show that combination therapy of bPEI/dual-specific TK gene with bevacizumab can increase the anti-cancer efficacy of gene therapy in malignant glioma of the spinal cord. We also found that even an injection of bPEI/dual-specific TK gene complexes alone or bevacizumab alone reduced the tumor area compared to the untreated control group (Fig. 5C). Bevacizumab is an FDAapproved drug with an anti-angiogenesis effect. It also has the effect of inhibition angiogenesis in tumors, thereby inhibiting tumor growth and causing hypoxia condition. As a result, it increases the effect of the dual-specific TK gene, although hypoxia condition induces VEGF expression.

The dual-specific TK gene increased the apoptosis of C6 glioma cells and reduced the side effects produced by tissue-specific promoters. ${ }^{33}$ Gene therapy using the HSV-TK suicide gene is a promising approach to treat tumors in the CNS ${ }^{34}$ However, it also induces non-specific cell death near the tumor tissue. Many studies have reported the ability of tissue-specific genes to reduce such side effects and enhance the effects of therapeutic genes. ${ }^{35} \mathrm{Oh}$, et al. ${ }^{16}$ reported that complexes of R7L10 peptide/glioblastoma-specific TK gene with bevacizumab increased the therapeutic effect of the HSV-TK gene on glioblastoma in the brain. Also, these complexes using a low dose of PEI did not show tissue damage after intravenous injection. The tissue-specific GFAP promoter (gfa2) has been shown to reduce the side effects of gene therapy and increase its specificity. ${ }^{36}$ The insertion of an Epo enhancer upstream of the tissue-specific promoter increases the expression of the TK gene under hypoxic conditions, resulting in a dual-specific gene expression system. ${ }^{12}$ In this study, the hypoxia/glioma dual-specific gene expression system efficiently induced the expression of the cancer suicide gene in IMSCTs.

The present study demonstrated that a combination therapy using hypoxia-glioma dual-specific TK gene and bevacizumab resulted in better maintenance of the walking function in rat hind-limbs compared to using any treatment method alone (Fig. 4). This result may be attributed to the bevacizumab-induced inhibition of angiogenesis and development of a hypoxia-like condition in the tumors. These results also led to an increase in the expression of the hypoxia-glioma dual-specific TK gene and apoptosis of tumor cells. Anti-angiogenic therapy combined with chemotherapy offers several potential advantages over conventional chemotherapy. ${ }^{37,38}$ Bevacizumab, an anti-angiogenic agent, targets VEGF and inhibits its expres- sion in tumors. ${ }^{39,40}$ Therefore, its use has been found to prevent angiogenesis, an effect that inhibits the growth of spinal cord tumors. ${ }^{4}$ Bevacizumab also reduces the side effects by limiting the amount and need for other chemotherapy or therapeutic genes. ${ }^{16}$

For the long-term study of spinal cord tumors, it is necessary that the combination therapy using both dual-specific TK gene and bevacizumab promotes the survival of the animals studied. A limitation of the present study was the use of C6 glioma cells of rats. Repeating the same experiments with a human tumor cell line will provide a better perspective. In this study, we demonstrated that the efficacy of dual-specific TK gene in the treatment of spinal cord tumor may be enhanced when combined with a bevacizumab injection. The combination treatment significantly reduced the tumor mass in the spinal cord and enhanced the walking function of the rat hind-limbs. These results suggest that the combination therapy using dual-specific TK gene and bevacizumab offers great potential for the treatment of spinal cord tumor.

\section{ACKNOWLEDGEMENTS}

This paper was supported by Wonkwang University in 2020 (2020-03-20-68).

\section{AUTHOR CONTRIBUTIONS}

Conceptualization: Yoon Ha. Data curation: So-Jung Gwak and Yoon Ha. Formal analysis: all authors. Funding acquisition: So-Jung Gwak and Yoon Ha. Investigation: So-Jung Gwak and Yoon Ha. Methodology: all authors. Project administration: So-Jung Gwak and Yoon Ha. Resources: Yoon Ha. Software analysis: Lihua Che. Supervision: Yoon Ha. Validation: all authors. Visualization: So-Jung Gwak and Yoon Ha. Writing—original draft: So-Jung Gwak and Yeomin Yun. Writing-review \&editing: Yoon Ha. Approval of final manuscript: all authors.

\section{ORCID iDs}

So-Jung Gwak

Lihua Che

Yeomin Yun

Minhyung Lee

Yoon $\mathrm{Ha}$ https://orcid.org/0000-0003-4642-5226 https://orcid.org/0000-0001-8925-0468 https://orcid.org/0000-0003-0927-107X https://orcid.org/0000-0002-7083-9296 https://orcid.org/0000-0002-3775-2324

\section{REFERENCES}

1. Bakhshi SK, Waqas M, Shakaib B, Enam SA. Management and outcomes of intramedullary spinal cord tumors: a single center experience from a developing country. Surg Neurol Int 2016;7:S617-22.

2. Samartzis D, Gillis CC, Shih P, O'Toole JE, Fessler RG. Intramedullary spinal cord tumors: part I-epidemiology, pathophysiology, and diagnosis. Global Spine J 2015;5:425-35.

3. Fernandes C, Costa A, Osório L, Lago RC, Linhares P, Carvalho B, et al. Current standards of care in glioblastoma therapy. In: De Vleeschouwer S, editor. Glioblastoma [Internet]. Brisbane (AU): Codon Publications; 2017. 
4. Gwak SJ, An SS, Yang MS, Joe E, Kim DH, Yoon DH, et al. Effect of combined bevacizumab and temozolomide treatment on intramedullary spinal cord tumor. Spine (Phila Pa 1976) 2014;39:E6573.

5. Uei H, Tokuhashi Y, Maseda M, Nakahashi M, Sawada H, Nakayama E, et al. Clinical results of multidisciplinary therapy including palliative posterior spinal stabilization surgery and postoperative adjuvant therapy for metastatic spinal tumor. J Orthop Surg Res 2018;13:30.

6. Pio L, Blanc T, de Saint Denis T, Irtan S, Valteau-Couanet D, Michon J, et al. Multidisciplinary surgical strategy for dumbbell neuroblastoma: a single-center experience of 32 cases. Pediatr Blood Cancer 2019;66 Suppl 3:e27670.

7. Alexiou GA, Vartholomatos E, Tsamis KI, Peponi E, Markopoulos G, A Papathanasopoulou V, et al. Combination treatment for glioblastoma with temozolomide, DFMO and radiation. J BUON 2019; 24:397-404.

8. Yang J, Shi Z, Liu R, Wu Y, Zhang X. Combined-therapeutic strategies synergistically potentiate glioblastoma multiforme treatment via nanotechnology. Theranostics 2020;10:3223-39.

9. Lee J, Kim E, Ryu SW, Choi C, Choi K. Combined inhibition of vascular endothelial growth factor receptor signaling with temozolomide enhances cytotoxicity against human glioblastoma cells via downregulation of Neuropilin-1. J Neurooncol 2016;128:29-34.

10. Lee CG, Heijn M, di Tomaso E, Griffon-Etienne G, Ancukiewicz M, Koike C, et al. Anti-vascular endothelial growth factor treatment augments tumor radiation response under normoxic or hypoxic conditions. Cancer Res 2000;60:5565-70.

11. Ferrara N, Hillan KJ, Novotny W. Bevacizumab (Avastin), a humanized anti-VEGF monoclonal antibody for cancer therapy. Biochem Biophys Res Commun 2005;333:328-35.

12. Hu YL, DeLay M, Jahangiri A, Molinaro AM, Rose SD, Carbonell WS, et al. Hypoxia-induced autophagy promotes tumor cell survival and adaptation to antiangiogenic treatment in glioblastoma. Cancer Res 2012;72:1773-83.

13. Hata N, Yoshimoto K, Hatae R, Kuga D, Akagi Y, Sangatsuda Y, et al. Add-on bevacizumab can prevent early clinical deterioration and prolong survival in newly diagnosed partially resected glioblastoma patients with a poor performance status. Onco Targets Ther 2017;10:429-37.

14. Lee HL, Lee HY, Yun Y, Oh J, Che L, Lee M, et al. Hypoxia-specific, VEGF-expressing neural stem cell therapy for safe and effective treatment of neuropathic pain. J Control Release 2016;226:21-34.

15. Kim HA, Park JH, Yi N, Lee M. Delivery of hypoxia and glioma dual-specific suicide gene using dexamethasone conjugated polyethylenimine for glioblastoma-specific gene therapy. Mol Pharm 2014;11:938-50.

16. Oh B, Han J, Choi E, Tan X, Lee M. Peptide micelle-mediated delivery of tissue-specific suicide gene and combined therapy with avastin in a glioblastoma model. J Pharm Sci 2015;104:1461-9.

17. Horst Mt, Brouwer E, Verwijnen S, Rodijk M, de Jong M, Hoeben $\mathrm{R}$, et al. Targeting malignant gliomas with a glial fibrillary acidic protein (GFAP)-selective oncolytic adenovirus. J Gene Med 2007; 9:1071-9.

18. Zheng C, Baum BJ. Evaluation of promoters for use in tissue-specific gene delivery. Methods Mol Biol 2008;434:205-19.

19. Ghulam Muhammad AK, Candolfi M, King GD, Yagiz K, Foulad $\mathrm{D}$, Mineharu Y, et al. Antiglioma immunological memory in response to conditional cytotoxic/immune-stimulatory gene therapy: humoral and cellular immunity lead to tumor regression. Clin Cancer Res 2009;15:6113-27.

20. Campillo N, Falcones B, Otero J, Colina R, Gozal D, Navajas D, et al. Differential oxygenation in tumor microenvironment modu- lates macrophage and cancer cell crosstalk: novel experimental setting and proof of concept. Front Oncol 2019;9:43.

21. Beppu T, Kamada K, Yoshida Y, Arai H, Ogasawara K, Ogawa A. Change of oxygen pressure in glioblastoma tissue under various conditions. J Neurooncol 2002;58:47-52.

22. Harris AL. Hypoxia--a key regulatory factor in tumour growth. Nat Rev Cancer 2002;2:38-47.

23. Lendahl U, Zimmerman LB, McKay RD. CNS stem cells express a new class of intermediate filament protein. Cell 1990;60:585-95.

24. Lothian C, Lendahl U. An evolutionarily conserved region in the second intron of the human nestin gene directs gene expression to CNS progenitor cells and to early neural crest cells. Eur J Neurosci 1997;9:452-62.

25. Zimmerman L, Parr B, Lendahl U, Cunningham M, McKay R, Gavin B, et al. Independent regulatory elements in the nestin gene direct transgene expression to neural stem cells or muscle precursors. Neuron 1994;12:11-24.

26. Gwak SJ, Yun Y, Yoon DH, Kim KN, Ha Y. Therapeutic use of $3 \beta$-[N-(N',N'-Dimethylaminoethane) Carbamoyl] cholesterolmodified PLGA nanospheres as gene delivery vehicles for spinal cord injury. PLoS One 2016;11:e0147389.

27. Barros Filho TE, Molina AE. Analysis of the sensitivity and reproducibility of the Basso, Beattie, Bresnahan (BBB) scale in Wistar rats. Clinics (Sao Paulo) 2008;63:103-8.

28. Vaillant B, Loghin M. Treatment of spinal cord tumors. Curr Treat Options Neurol 2009;11:315-24.

29. Chanchotisatien A, Xiong J, Yu J, Chu S. Exophytic primary intramedullary spinal cord glioblastoma: case report and critical review of literature. World Neurosurg 2019;122:573-6.

30. Kutluk T, Varan A, Kafalı C, Hayran M, Söylemezoğlu F, Zorlu F, et al. Pediatric intramedullary spinal cord tumors: a single center experience. Eur J Paediatr Neurol 2015;19:41-7.

31. Gwak SJ, Lee JS. Suicide gene therapy by amphiphilic copolymer nanocarrier for spinal cord tumor. Nanomaterials (Basel) 2019;9: 573-89.

32. Okuda T, Tasaki T, Nakata S, Yamashita K, Yoshioka H, Izumoto S, et al. Efficacy of combination therapy with MET and VEGF inhibitors for MET-overexpressing glioblastoma. Anticancer Res 2017; 37:3871-6.

33. Huang Q, Pu P, Xia Z, You Y. Exogenous wt-p53 enhances the antitumor effect of HSV-TK/GCV on C6 glioma cells. J Neurooncol 2007;82:239-48.

34. Johansson CB, Lothian C, Molin M, Okano H, Lendahl U. Nestin enhancer requirements for expression in normal and injured adult CNS. J Neurosci Res 2002;69:784-94.

35. Sonawane AR, Platig J, Fagny M, Chen CY, Paulson JN, Lopes-Ramos CM, et al. Understanding tissue-specific gene regulation. Cell Rep 2017;21:1077-88.

36. Tredway TL. Minimally invasive approaches for the treatment of intramedullary spinal tumors. Neurosurg Clin N Am 2014;25:327-36.

37. Ma J, Waxman DJ. Combination of antiangiogenesis with chemotherapy for more effective cancer treatment. Mol Cancer Ther 2008; 7:3670-84.

38. Comunanza V, Bussolino F. Therapy for cancer: strategy of combining anti-angiogenic and target therapies. Front Cell Dev Biol 2017;5:101.

39. Lambrechts D, Lenz HJ, de Haas S, Carmeliet P, Scherer SJ. Markers of response for the antiangiogenic agent bevacizumab. J Clin Oncol 2013;31:1219-30.

40. Peng CL, Lin HC, Chiang WL, Shih YH, Chiang PF, Luo TY, et al. Anti-angiogenic treatment (Bevacizumab) improves the responsiveness of photodynamic therapy in colorectal cancer. Photodiagnosis Photodyn Ther 2018;23:111-8. 